\title{
ChemComm
}

\section{Rhodium catalyzed synthesis of difluoromethyl cyclopropanes $\dagger$}

Cite this: Chem. Commun., 2016, 52,13783

Received 23rd September 2016, Accepted 31st October 2016

DOI: $10.1039 / c 6 c c 07745 e$

www.rsc.org/chemcomm

\author{
Katharina J. Hock, Lucas Mertens and Rene M. Koenigs*
}

\begin{abstract}
Difluoromethyl-substituted cyclopropanes still remain one of the most challenging class of substrates. Despite significant progress in modern chemistry, an atom-economic and concise synthesis has not been described to date. Herein, we describe the first method for their catalytic, one-step synthesis using difluoromethyl diazomethane and a rhodium(॥) catalyst.
\end{abstract}

In recent years, novel methods for the introduction of difluoromethyl groups have attracted the interest of organic chemists from all fields. ${ }^{1,2}$ Although the difluoromethyl group differs only in a single fluorine atom from the well-studied trifluoromethyl group, it possesses significantly altered properties making difluoromethylated compounds attractive synthetic targets. While trifluoromethyl groups are inert from a chemical and biological perspective, the difluoromethyl group possesses lower lipophilicity and increased polarity. Moreover, it is an alcohol or thiol bioisostere and can act as a hydrogen bond donor and is thus highly attractive to drug discovery programs. ${ }^{1 b}$

Over the past decade, trifluoromethyl diazomethane found regular application in organic synthesis and led to a flourishing area of research. ${ }^{3,4}$ Interestingly, while trifluoromethyl diazomethane is known since $1943,{ }^{5}$ the difluoromethyl-substituted analogue was first described only in $2015^{6}$ and applications of this novel reagent in organic synthesis are still scarce., Against this background, we became interested in the catalytic synthesis of difluoromethyl-substituted cyclopropanes, which should be accessible via this newly introduced reagent. ${ }^{8}$

To date, there are only two reports claiming 1-difluoromethyl2-aryl cyclopropanes, yet without describing the synthesis. ${ }^{9}$ The synthesis of difluoromethyl cyclopropanes in general has been studied only to a very limited extent. ${ }^{10}$ Leadbeater and coworkers and Hanamoto and co-workers reported the synthesis of this class of substances applying ring closure reactions using tedious multi-step syntheses. ${ }^{10 a, b}$ De Meijere and co-workers

RWTH Aachen University, Institute of Organic Chemistry, Landoltweg 1, D-52074 Aachen, Germany. E-mail: rene.koenigs@rwth-aachen.de

$\dagger$ Electronic supplementary information (ESI) available. See DOI: 10.1039/c6cc07745e

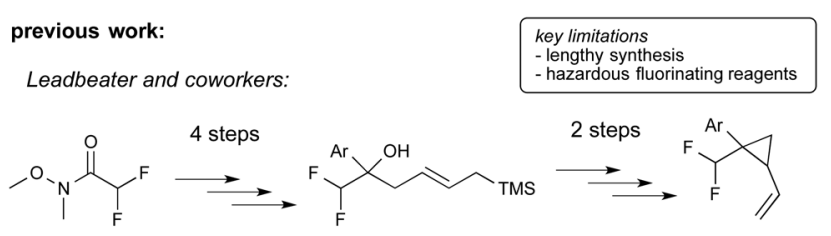

de Meijere and coworkers
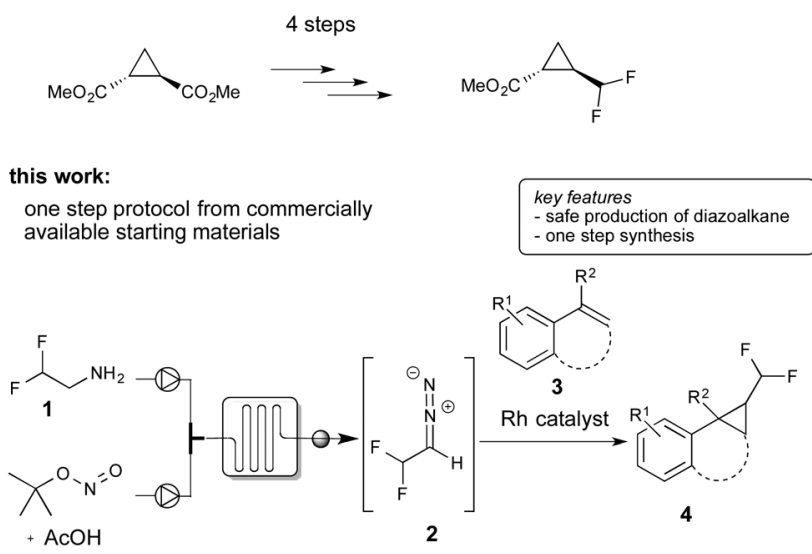

Scheme 1 Synthetic approaches towards difluoromethyl cyclopropanes.

reported a multi-step synthesis of difluoromethyl cyclopropanes starting from cyclopropyl esters and by application of hazardous and highly reactive fluorinating reagents for the introduction of the difluoromethyl group. ${ }^{10 c}$ To the best of our knowledge no catalytic methods for the efficient one-step preparation from readily available starting materials has been described yet (Scheme 1).

Difluoromethyl-substituted cyclopropanes find few applications, ${ }^{9,11}$ such as in the ROR-gamma modulator $(6)^{9 a}$ or as insecticides (7). ${ }^{9 b, 11 b}$ The most prominent compound containing a difluoromethyl cyclopropane is voxilaprevir (5), which is currently in phase II clinical trials for treatment of hepatitis $\mathrm{C}$ virus infections (Fig. 1). ${ }^{11 c, d}$

We started our investigations towards difluoromethyl-substituted cyclopropanes by evaluating different batch transformations. 

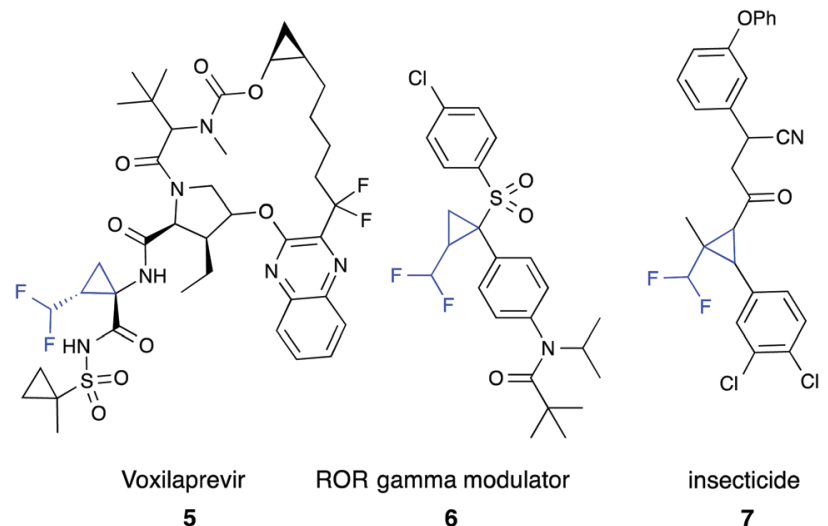

Fig. 1 Difluoromethyl cyclopropanes in medicinal and agrochemical research.

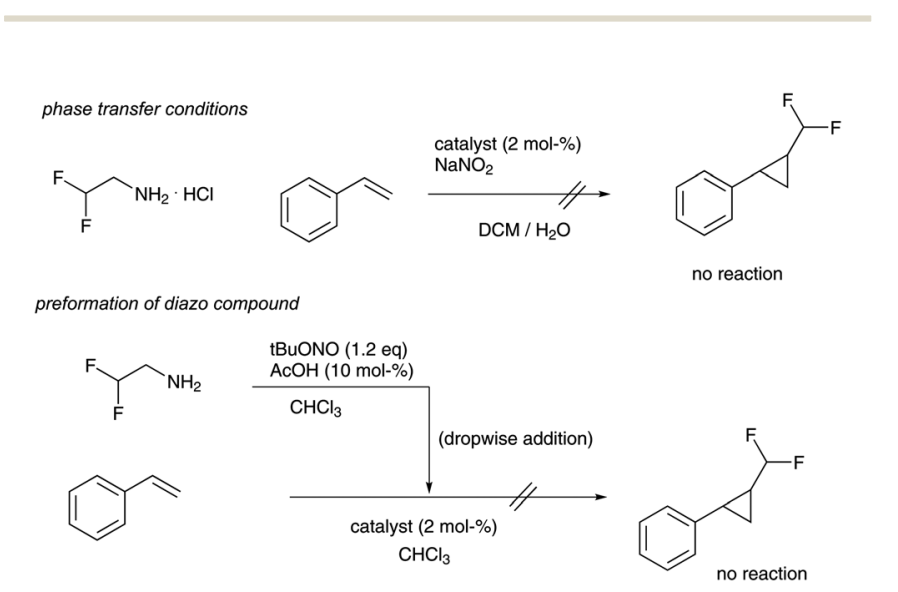

Scheme 2 Attempts to difluoromethyl cyclopropane synthesis in batch reactions (catalysts investigated $=\mathrm{Rh}_{2} \mathrm{OAc}_{4}, \mathrm{Ru}(\mathrm{TPP}) \mathrm{CO}, \mathrm{Fe}(\mathrm{TPP}) \mathrm{Cl}, \mathrm{Rh}_{2} \mathrm{Piv}_{4}$ ).

First, we investigated phase transfer protocols, ${ }^{4 c, i}$ that find regular application in reactions using trifluoromethyl diazomethane, yet the desired product could not be observed using different cyclopropanation catalysts. Similarly, preformation of difluoromethyl diazomethane and subsequent dropwise addition of the reagent to styrene and different cyclopropanation catalysts failed completely (Scheme 2). This observation is in sharp contrast to trifluoromethyl diazomethane and the corresponding cyclopropanation reactions. ${ }^{4}$

Recently, we reported on the continuous-flow synthesis of fluoroalkyl-substituted diazoalkanes and their application in pyrazole and pyrazoline synthesis. ${ }^{7,12,13}$ As conventional batch reactions did not provide the desired product, we became interested in evaluating the flow protocol in this cyclopropanation reaction.

For the continuous-flow generation of difluoromethyl diazomethane, we used a micromixer (Little Things Factory, MR-LAB Type MST, mixer volume: $200 \mu \mathrm{L}$ ) to mix a stream of difluoroethylamine with a mixture of $t \mathrm{BuONO}$ and $\mathrm{AcOH}$. We then examined a range of different conditions, e.g. temperature, amount of acetic acid and residence time in the microreactor, by monitoring aliquots of the outlet by NMR spectroscopy. $40 \mathrm{~mol} \%$ of acetic acid and a residence time of 2 minutes in the
Table 1 Optimization of reaction conditions

\begin{tabular}{|c|c|c|c|c|}
\hline$\stackrel{\lambda}{+A c}$ & $\begin{array}{l}\text { micr } \\
200 \\
75^{\circ}\end{array}$ & 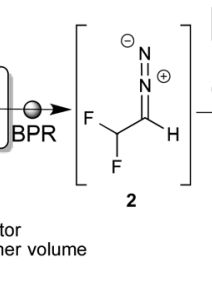 & $\begin{array}{c}3 \mathrm{a} \\
(\mathrm{mol}-\%) \\
\stackrel{\mathrm{HCl} l_{3}}{\longrightarrow}\end{array}$ & $\gamma^{F}$ \\
\hline Entry $^{a}$ & Catalyst & Loading (mol\%) & Solvent & Yield $^{b}(\%)$ \\
\hline 1 & $\mathrm{Fe}$ (TPP)Cl & 2 & $\mathrm{CHCl}_{3}$ & Traces \\
\hline 2 & $\mathrm{Ru}(\mathrm{TPP}) \mathrm{CO}$ & 2 & $\mathrm{CHCl}_{3}$ & No ret. \\
\hline 3 & $\mathrm{Co}$ (salen) & 2 & $\mathrm{CHCl}_{3}$ & No ret. \\
\hline 4 & CuOTf & 2 & $\mathrm{CHCl}_{3}$ & No rct. \\
\hline 5 & {$\left[\mathrm{Cp}^{*} \mathrm{IrCl}_{2}\right]_{2}$} & 2 & $\mathrm{CHCl}_{3}$ & No ret. \\
\hline 6 & {$\left[\mathrm{Cp}^{*} \mathrm{RhCl}_{2}\right]_{2}$} & 2 & $\mathrm{CHCl}_{3}$ & No rct. \\
\hline 7 & $\operatorname{Pd}(\text { acac })_{2}$ & 2 & $\mathrm{CHCl}_{3}$ & No rct. \\
\hline 8 & $\mathrm{Rh}_{2} \mathrm{OAc}_{4}$ & 2 & $\mathrm{CHCl}_{3}$ & 12 \\
\hline 9 & $\mathrm{Rh}_{2} \mathrm{Piv}_{4}$ & 2 & $\mathrm{CHCl}_{3}$ & 6 \\
\hline 10 & $\mathrm{Rh}_{2} \mathrm{TPA}_{4}$ & 2 & $\mathrm{CHCl}_{3}$ & No ret. \\
\hline 11 & $\mathrm{Rh}_{2} \mathrm{esp}_{2}$ & 2 & $\mathrm{CHCl}_{3}$ & 24 \\
\hline 12 & $\mathrm{Rh}_{2} \mathrm{esp}_{2}$ & 5 & $\mathrm{CHCl}_{3}$ & $67^{c}$ \\
\hline 13 & $\mathrm{Rh}_{2} \mathrm{esp}_{2}$ & 5 & $\mathrm{CHCl}_{3}$ & $13^{d}$ \\
\hline
\end{tabular}

${ }^{a}$ A solution of difluoroethylamine $(0.2 \mathrm{M}, 4$ eq. $)$ in $\mathrm{CHCl}_{3}$ and a mixture of $\mathrm{AcOH}$ (1.6 eq.) and $t \mathrm{BuONO}\left(0.24 \mathrm{M}, 4.8\right.$ eq.) in $\mathrm{CHCl}_{3}$ were transferred by syringe pump into the microreactor (Little Things Factory, MR Lab, Type MST, inner volume $200 \mu \mathrm{L}$ ) at a constant flow rate of $50 \mu \mathrm{L} \mathrm{min}{ }^{-1}$ for each syringe. The microreactor was heated to $75{ }^{\circ} \mathrm{C}$ and the outlet of the microreactor was connected to a back pressure regulator (40 psi). The reaction solution from the microreactor was added to a standard reaction flask at room temperature under $\mathrm{Ar}$ atmosphere containing styrene $\left(0.4 \mathrm{mmol}, 1 \mathrm{eq}\right.$.) and the appropriate catalyst in $4 \mathrm{~mL} \mathrm{CHCl}_{3}$. ${ }^{b}$ Yields determined by ${ }^{19} \mathrm{~F}-\mathrm{NMR}$ of the crude reaction mixture using $\alpha, \alpha, \alpha$-trifluorotoluene as internal standard. ${ }^{c}$ Isolated yield after column chromatography. ${ }^{d}$ Reaction temperature of the cyclopropanation reaction $0{ }^{\circ} \mathrm{C}$.

microreactor at $75{ }^{\circ} \mathrm{C}$ proved to yield the desired difluoromethyl diazomethane in about $40 \%$ yield. With the optimal conditions for the preparation of difluoromethyl diazomethane in hand, we next assessed the cyclopropanation reaction of styrene with difluoromethyl diazomethane, prepared in continuous-flow, using a broad variety of different cyclopropanation catalysts (Table 1).

Initially, we examined iron and ruthenium porphyrine complexes, which were already demonstrated to be versatile catalysts for the preparation of trifluoromethyl substituted cyclopropanes. To our surprise, only trace amounts of the desired difluoromethylsubstituted cyclopropane could be observed using Fe[TPP]Cl. Other typical cyclopropanation catalysts, such as Ru[TPP]CO, $\mathrm{Co}$ [salen] complexes or $\mathrm{Cu}(\mathrm{I})$, or $\mathrm{Ru}(\mathrm{III})$ and $\mathrm{Ir}(\mathrm{III})$ complexes failed completely and no product was observed.

Interestingly, both $\mathrm{Rh}_{2} \mathrm{OAc}_{4}$ and $\mathrm{Rh}_{2} \mathrm{Piv}_{4}$ gave minor amounts of the desired cyclopropanation product, while $\mathrm{Rh}_{2} \mathrm{TPA}_{4}$ failed to yield the cyclopropane. These results are in sharp contrast to previously reported cyclopropanation reactions using trifluoromethyl diazomethane, which we assume to result from (a) the highly instable nature of difluoromethyl diazomethane and (b) from facile $\beta$-hydride elimination of the intermediate metal-carbene complex when using difluoromethyl diazomethane. We thus hypothesized, that sterically more demanding catalysts would reduce the rate of $\beta$-hydride elimination and result in higher yield of the desired cyclopropane. 
To our delight, $\mathrm{Rh}_{2} \mathrm{esp}_{2}{ }^{14}$ proved significantly better and we could observe increased yields of the cyclopropanation product. Encouraged by these results we increased the catalyst loading to $5 \mathrm{~mol} \%$ and we could finally isolate the desired difluoromethylated cyclopropane $4 a$ for the first time in $67 \%$ yield.

In further experiments we investigated the substrate scope of this transformation (Table 2). Using our continuous-flow protocol for the preparation of difluoromethyl diazomethane, we could show that a range of different styrenes can be converted to the corresponding difluoromethyl-substituted cyclopropanes in

Table 2 Scope of the cyclopropanation reaction
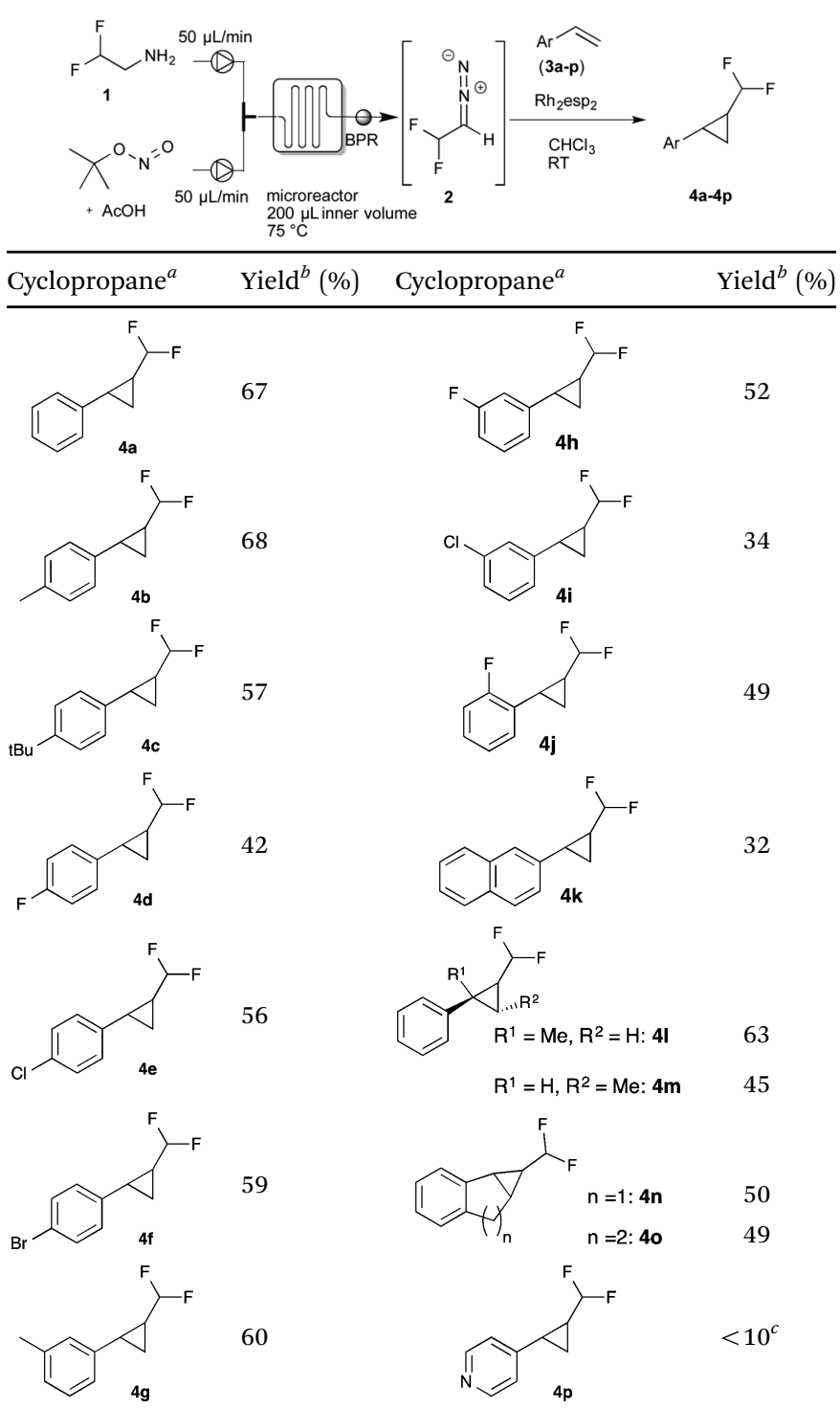

${ }^{a}$ A solution of difluoroethylamine ( $0.2 \mathrm{M}, 4$ eq.) in $\mathrm{CHCl}_{3}$ and a mixture of $\mathrm{AcOH}$ (1.6 eq.) and $t \mathrm{BuONO}\left(0.24 \mathrm{M}, 4.8\right.$ eq.) in $\mathrm{CHCl}_{3}$ were transferred by syringe pump into the microreactor (Little Things Factory, MR Lab, Type MST, inner volume $200 \mu \mathrm{L}$ ) at a constant flow rate of $50 \mu \mathrm{L} \mathrm{min}{ }^{-1}$ for each syringe. The microreactor was heated to $75{ }^{\circ} \mathrm{C}$ and the outlet of the microreactor was connected to a back pressure regulator (40 psi). The reaction solution the microreactor was added to a standard reaction flask under $\mathrm{Ar}$ atmosphere containing olefine $\left(0.4 \mathrm{mmol}, 1\right.$ eq.) and $\mathrm{Rh}_{2} \mathrm{esp}_{2}$ $(5 \mathrm{~mol} \%)$ in $4 \mathrm{~mL} \mathrm{CHCl}{ }_{3} \cdot{ }^{b}$ Isolated yield after column chromatography. ${ }^{c}$ Determined by NMR. moderate to good yield. This transformation is particularly useful, as our newly developed protocol allows for the first time an efficient synthesis of difluoromethyl-substituted cyclopropanes in an operationally simple one-step protocol from cheap, commercially available olefins and amines.

In general electron donating and electron-withdrawing substituents are well tolerated and the corresponding cyclopropanes can be isolated in moderate to good yield. Moreover, different substitution patterns, such as meta-substituents are compatible under these reaction conditions and the desired reaction products can be obtained in good yield.

Further investigations concentrated on substituted styrenes. We probed $\alpha$-methyl styrene and trans- $\beta$ methyl styrene under these reaction conditions and were delighted to observe that the corresponding cyclopropanes ( $\mathbf{4 l}$ and $\mathbf{4 m}$ ) can be isolated in good yield. Similarly, indene and dihydronaphthalene gave the desired cyclopropanation products ( $\mathbf{4 n}$ and $\mathbf{4 o}$ ) in moderate yield. Heterocyclic compounds (4p) proved to give only unsatisfactory yield of the desired cyclopropane. Allylbenzene, as a non-aromatic olefinic substrate, did not provide the desired product. The diastereomeric ratio of all cyclopropanes obtained was in the range of 1.2-1.7:1. Only in the case of 40 we observed a slightly higher diastereomeric ratio of $3: 1$.

In summary, we have developed a new protocol that allows for the first time a catalytic one-step synthesis of difluoromethyl cyclopropanes. A key element for the development of this protocol is the efficient preparation of difluoromethyl diazomethane in continuous-flow. Subsequent application in rhodium(II) catalyzed cyclopropanation reactions provide for the first time difluoromethyl substituted cyclopropanes in a one-step protocol and good isolated yields.

\section{Notes and references}

1 Selected references: (a) G. K. S. Prakash and J. Hu, Acc. Chem. Res., 2007, 40, 921; (b) J. Hu, W. Zhang and F. Wang, Chem. Commun., 2009, 7465-7478; (c) J. Hu and C. Ni, Sci. Synth., C-1 Build. Blocks Org. Synth., 2014, 2, 409; (d) C. Ni, J. Liu, L. Zhang and J. Hu, Angew. Chem., Int. Ed., 2007, 46, 786; (e) C. Ni and J. Ju, Chem. Soc. Rev., 2016, 45, 5441-5454.

2 (a) D. Barnes-Seeman, J. Beck and C. Springer, Curr. Top. Med. Chem., 2014, 14, 855-864; (b) Fluorine in Pharmaceutical and Medicinal Chemistry: From Biophysical Aspects to Clinical Applications, ed. V. Gouverneur and K. Müller, Imperial College Press, London, 2012.

3 Review on fluoroalkyl-substituted diazoalkanes: L. Mertens and R. M. Koenigs, Org. Biomol. Chem., 2016, DOI: 10.1039/C6OB01618A.

4 Selected references: (a) P. Le Maux, S. Juillard and G. Simonneaux, Synthesis, 2006, 1701; (b) P. K. Mykhailiuk, S. Afonin, G. V. Palamarchuk, O. V. Shishkin, A. S. Ulrich and I. V. Komarov, Angew. Chem., Int. Ed., 2008, 47, 5765; (c) B. Morandi and E. M. Carreira, Angew. Chem., Int. Ed., 2010, 49, 938; (d) B. Morandi, B. Mariampillai and E. M. Carreira, Angew. Chem., Int. Ed., 2011, 50, 1101; (e) T.-R. Li, S.-W. Duan, W. Ding, Y.-Y. Liu, J. R. Chen, L.-Q. Lu and W.-J. Xiao, J. Org. Chem., 2014, 79, 2296-2302; $(f)$ B. Morandi, J. Cheang and E. M. Carreira, Org. Lett., 2011, 13, 3080; (g) O. S. Artamonov, E. Y. Slobodyanyuk, D. M. Volochnyuk, I. V. Komarov, A. A. Tolmachev and P. K. Mykhailiuk, Eur. J. Org. Chem., 2014, 3592-3598; (h) C.-L. Zhu, L.-J. Yang, S. Li, Y. Zheng and J.-A. Ma, Org. Lett., 2015, 17, 3442; (i) E. Y. Slobodyanyuk, O. S. Artamonov, O. V. Shishkin and P. K. Mykhailiuk, Eur. J. Org. Chem., 2014, 2487.

5 H. Gilman and R. G. Jones, J. Am. Chem. Soc., 1943, 65, 1458-1460.

6 P. K. Mykhailiuk, Angew. Chem., Int. Ed., 2015, 54, 6558-6561.

7 L. Mertens, K. J. Hock and R. M. Koenigs, Chem. - Eur. J., 2016, 22, 9542 . 
8 Selected reviews: (a) H. Lebel, J. F. Marcoux, C. Molinaro and A. B. Charette, Chem. Rev., 2003, 103, 977; (b) J. Hansen and H. M. L. Davies, Coord. Chem. Rev., 2008, 252, 545; (c) H. M. L. Davies and J. R. Denton, Chem. Soc. Rev., 2009, 38, 3061; (d) A. Ford, H. Miel, A. Ring, C. N. Slattery, A. R. Maguire and M. A. McKervey, Chem. Rev., 2015, 115, 9981.

9 Reports claiming 1-difluoromethyl-2-aryl cyclopropanes: (a) R. H. Hutchings, J. H. Jones, J. Chao, I. J. Enyedy and D. Marcotte, WO 2014028669, Biogen Idec Ma., 2014; (b) K. Yoshio, JP 57040440, 1982.

10 Reports on the synthesis of difluoromethyl cyclopropanes: (a) C. B. Kelly, M. A. Mercadante, E. R. Carnaghan, M. J. Doherty, D. C. Fager, J. J. Hauck, A. E. MacInnis, L. J. Tilley and N. E. Leadbeater, Eur. J. Org. Chem., 2015, 4071; (b) T. Ishikawa, N. Kasai, Y. Yamada and T. Hanamoto, Tetrahedron, 2015, 71, 1254; (c) A. de Meijere, S. I. Kuzhushkov, D. S. Yufit, C. Grosse, M. Kaiser and V. A. Raev, Beilstein J. Org. Chem., 2014, 10, 2844.

11 Selected references: (a) J. R. Allen, A. Amegadzie, M. P. Bourbeau, J. A. Brown, J. J. Chen, Y. Cheng, M. J. Frohn, A. Guzman-Perez, P. E. Harrington, L. Liu, Q. Liu, J. D. Low, V. V. Ma, J. Manning, A. E. Minatti, T. T. Nguyen, N. Nishmura, M. H. Norman, L. H. Pettus, A. J. Pickrell, W. Qian, S. Rumfelt, R. M. Rzasa, A. C. Siegmund, M. M. Stec, R. White and Q. Xue, WO 2016022724, Amgen, 2016; (b) T. Mori, K. Ujihara, O. Matsumoto, K. Yanagi and N. Matsuo, J. Fluorine Chem., 2007, 128, 1174; (c) A. Cagulada, J. Chan, L. Chan, D. A. Colby, K. K. Karki, D. Kato, K. A. Keaton, S. Kondapally, C. Levins, A. Littke, R. Martinez, D. Pcion, T. Reynolds, B. Ross, M. Sangi, A. J. Schrier, P. Seng, D. Siegel, N. Shapiro, D. Tang, J. G. Taylor, J. Tripp, A. W. Waltman and L. Yu, US 20150175626, Gilead, 2015; (d) M. Rodriguez-Torres, S. Glass, J. Hill, B. Freilich, D. Hassman, A. M. Di Bisceglie, J. G. Taylor, B. J. Kirby, H. Dvory-Sobol, J. C. Yang, D. An, L. M. Stamm, D. M. Brainard, S. Kim, D. Krefetz, W. Smith, T. Marbury and E. Lawitz, J. Viral Hepatitis, 2016, 23, 614.

12 Selected review articles: (a) S. T. R. Mueller and T. Wirth, ChemSusChem, 2015, 8, 245; (b) R. L. Hartman, J. P. McMullen and K. F. Jensen, Angew. Chem., Int. Ed., 2011, 50, 7502; (c) J. Wegner, S. Ceylan and A. Kirschning, Chem. Commun., 2011, 47, 4583-4592; (d) S. V. Ley, Chem. Rev., 2012, 12, 378; (e) C. Wiles and P. Watts, Green Chem., 2012, 14, 38; $(f)$ T. H. Rehm, Chem. Eng. Technol., 2016, 39(1), 66; $(g)$ B. J. Deadman, S. G. Collins and A. R. Maguire, Chem. - Eur. J., 2015, 21, 2298; (h) M. Movsisyan, E. I. P. Delbeke, J. K. E. T. Berton, C. Battilocchio, S. V. Ley and C. V. Stevens, Chem. Soc. Rev., 2016, 45, 4892.

13 Fluoroalkyl substituted diazoalkanes in flow chemistry: B. Pieber and C. O. Kappe, Org. Lett., 2016, 18, 1076.

14 C. G. Espino, K. W. Fiori, M. Kim and J. Du Bois, J. Am. Chem. Soc., 2004, 126, 15378. 